\title{
EFFICIENCY INCREASE IN THE AXIS DRIVE PROCESS
}

\section{Weidson Diego Andrade Soares ${ }^{1}$, Macley Bernardes Batista ${ }^{2}$}

\footnotetext{
${ }^{1}$ Weidson Diego Andrade Soares, Graduando (a) do curso de Engenharia Mecânica Uninorte Laureate

${ }^{2}$ Macley Bernardes Batista, graduando(a) do curso de Engenharia Mecânica da Uninorte laurate
}

Email: weidsonsoares@hotmail.com

Received: June $26^{\text {th }}, 2019$

Accepted: August 16 $16^{\text {th }}, 2019$

Published: September $30^{\text {th }}$, 2019

Copyright @2016 by authors and Institute of Technology Galileo of Amazon (ITEGAM).

This work is licensed under the Creative Commons Attribution International License (CC BY 4.0). https://creativecommons.org/lice nses/by/4.0/

\begin{abstract}
The increased efficiency in the drilling process in the secondary axis of transmission axis aims at balancing the secondary axis line and increasing efficiency. The line is composed of eight machines being: Deep Hole CNC Lathe and Hole of Lubrication. which aims to objectify and apply this methodology in the secondary line, such application will be made in the company of Polo Industrial of Manaus with the purpose of improvement and reduction of costs, whose specific objective is to identify, mitigate and eliminate problems of qualities such as: reducing the consumption of tools in the drilling and lubrication process, increase process efficiency and reduce the amount of overtime in the industry.
\end{abstract}

Keywords: Kaizen; Shaft transmission; Efficiency; Stepped drill

\section{AUMENTO DE EFICIÊNCIA NO PROCESSO DE FURAÇÃO DE EIXO TRANSMISSÃO}

\section{RESUMO}

O aumento de eficiência no processo de furação na linha secundária de Eixo transmissão tem como objetivo o balanceamento da linha de eixo secundário e aumento de eficiência. A linha é composta de oito máquinas sendo: Furo profundo Torno CNC e Furo de lubrificação. que visa objetivar e aplicar esta metodologia na linha secundária, tal aplicação será feita na empresa do Polo Industrial de Manaus com intuito de melhoria e redução de custos, que tem como objetivo específicos identificar, atenuar e eliminar problemas de qualidades como: reduzir o consumo de ferramentas no processo de furo e lubrificação, aumentar a eficiência no processo e reduzir a quantidades de horas extraordinárias no setor.

Palavras-chave: Kaizen; Eixo transmissão; Eficiência; Broca escalonada

\section{INTRODUÇÃO}

Temos como base a manufatura enxuta ou lean manufacturing que vai além de uma ferramenta de gerenciamento, se trata de uma filosofia, criada pelo sistema Toyota de produção, com o objetivo de visualizar e atuar nos desperdícios que as empresas apresentam, melhorando a competitividade na indústria produzindo somente o necessário, na quantidade que precisam, com qualidade e no momento certo.

Durante o desenvolvimento deste projeto será abordado assuntos referentes a Lean Manufacturing, ferramentas da qualidade, Kaizen e usinagem. Este projeto visa melhorias de processo de produção (Kaizen) na linha de eixo transmissão nas furadeiras CNC de processo de furo de lubrificação, devido a problemas como: baixa eficiência na linha Secundária de Eixo Transmissão, aumento nas horas de trabalho (hora extra) e um auto índice na diminuição de qualidade nas peças produzidas pela empresa relacionadas ao furo de lubrificação. Com o propósito de sanar esses problemas será aplicada novas ferramentas na empresa do Polo Industrial líder mundial no segmento de produção de componentes mecânicos para o mercado automotivo de duas e quatro rodas, sendo pioneira na introdução do processo de forjamento no pólo Industrial de Manaus. Este processo é um dos pilares do grupo, cuja tecnologia permite a produção de forjados 
com o mínimo de sobre metal para usinagem. O método kaizen que será aplicado na empresa foi direcionado para o Aumento de eficiência no processo de furo de lubrificação, balanceamento da linha e redução dos problemas de qualidade relacionados ao furo deslocado e quebra de broca, assim melhorando a produtividade da linha e garantindo a qualidade do produto.

O objetivo principal é aplicar a metodologia KAIZEN, na linha secundária de eixo de transmissão, da empresa do PIM.

Para alcançar tais objetivos será aplicada tal metodologia, buscando os objetivos específicos que no qual serão : atenuar ou eliminar os problemas de qualidade, na linha secundaria de eixo de transmissão no processo de furo e lubrificação, diminuir o consumo de ferramentas no processo de furo de lubrificação e aumentar a eficiência do processo e diminuir a quantidade de horas extras.

\section{CONCEITO DE MANUFATURA EXUTA (LEAN MANUFACTURING)}

A Produção Enxuta surgiu no Japão, no período pós Segunda Guerra Mundial, cuja proeminente aplicação se deu na Toyota Motor Company. Devastado pela guerra, o Japão não dispunha de recursos para realizar altos investimentos necessários para a implantação da produção em massa, que caracterizava o sistema implantado por Henry Ford e General Motors. Além disso, no país existiam outras séries de problemas e desafios a serem contornados como: mercado interno limitado e demandando vasta variedade de produtos; mão-de-obra organizada, existência de vários fabricantes de veículos do mundo, interessados em ingressar no Japão, dentre outros.

A partir daí, surgiu a necessidade de se criar um novo modelo gerencial, nascendo, assim, o Sistema Toyota de Produção ou Manufatura Enxuta (Lean Manufacturing), estruturado por TAIICHI OHNO, vice-presidente da Toyota. Os objetivos fundamentais deste novo sistema caracterizaram-se por qualidade e flexibilidade do processo, ampliando sua capacidade de produzir e competir no cenário internacional.

O conceito de Manufatura Enxuta se disseminou pelo mundo e várias são as definições desta filosofia, conforme apresentado abaixo:

“A eliminação de desperdícios e elementos desnecessários a fim de reduzir custos; a ideia básica é produzir apenas o necessário, no momento necessário e na quantidade requerida [1]." "A busca de uma tecnologia de produção que utilize a menor quantidade de equipamentos e mão-de-obra para produzir bens sem defeitos no menor tempo possível, com o mínimo de unidades intermediárias, entendendo como desperdício todo e qualquer elemento que não contribua para o atendimento da qualidade, preço ou prazo requeridos pelo cliente. Eliminar todo desperdício através de esforços concentrados da administração, pesquisa e desenvolvimento, produção, distribuição e todos os departamentos da companhia [2]." Um dos conceitos fundamentais da Manufatura Enxuta é a melhoria contínua (chamado de Kaizen), considerada a chave do sucesso dos métodos japoneses de produção. O sistema de produção japonês é constituído para encorajar mudanças e aperfeiçoamentos constantes, como parte das operações diárias. Para alcançar o Kaizen, a gerência aproveita a experiência coletiva de todos os seus trabalhadores e valoriza a solução de problemas em conjunto. A Produção Enxuta surgiu como um sistema de manufatura cujo foco é otimizar os processos e procedimentos através da redução contínua de desperdícios, como, por exemplo, excesso de inventário entre as estações de trabalho, bem como tempos de espera elevados.
$\mathrm{Na}$ visão de [3], “a Produção Enxuta é o resultado da eliminação de sete tipos clássicos de desperdícios, também denominado de perdas, existentes dentro de uma empresa".

\section{II.1 AS SETE PERDAS}

\section{II.1.2 PERDA POR PROCESSAMENTO}

E processamento que consiste em máquinas ou equipamentos usados de modo inadequado quanto à capacidade ou culpabilidade de desempenhar uma operação.

\section{II.1.2 PERDA POR MOTIVAÇÃO NAS OPERAÇÕES}

Esta perda acontece pela diferença entre trabalho e movimento. Relacionam-se aos movimentos desnecessários realizados pelos operadores na execução de uma operação. Por exemplo, é a ação de quem realiza algum tipo de seleção ou procura peças sobre a bancada de trabalho ou qualquer movimento de um membro de time ou máquina o qual não adiciona valor.

\section{II.1.3 PERDA POR PRODUTOS DEFEITUOSOS OU RETRABALHO}

A perda por fabricação de produtos defeituosos é o resultado da geração de produtos com alguma característica de qualidade fora do especificado, e que por isso não satisfaz requisitos de uso. Produzir produtos defeituosos significa desperdiçar materiais, disponibilidade de mão de obra, disponibilidade de equipamentos, movimentação de materiais defeituosos, armazenagem de materiais defeituosos, inspeção de produtos, entre outros.

\section{II.1.4 PERDA POR ESTOQUE}

É a perda sob a forma de estoque de matéria-prima, material em processamento e produto acabado. É o recurso financeiro "aprisionado" no sistema produtivo. Significam desperdícios de investimento e espaço.

\section{II.1.5 PERDA POR SUPERPRODUÇÃO}

A perda por superprodução pode ser por quantidade, que é a produção além do volume programado (sobram peças), ou por antecipação, que é a perda por produzir antes do momento necessário, em que produtos fabricados ficarão estocados aguardando a ocasião de serem consumidos ou processados por etapas posteriores.

\section{II.1.6 PERDA POR TEMPO DE ESPERA}

Este tipo de perda consiste no tempo em que nenhum processamento, transporte ou inspeção é executado. Existem três tipos de perda por espera: no processo, quando ocorre a falta ou atraso na matéria-prima e um lote inteiro fica aguardando a operação da máquina para iniciar sua produção; do lote, quando peças já passaram por determinado processo e tem que esperar todas as outras peças do lote para poder seguir a próxima etapa; e do operador, quando o operário permanece ocioso, assistindo uma máquina em operação. 


\section{II.1.7 PERDA POR TRANSPORTE}

São realizados deslocamentos desnecessários ou estoques temporários. Encaradas como desperdícios de tempo e recursos, as atividades de transporte e movimentação devem ser eliminadas ou reduzidas ao máximo, através da elaboração de um arranjo físico adequado, que minimize as distâncias a serem percorridas. Além disso, custos de transporte podem ser reduzidos se o material for entregue no local de uso.

\section{USINAGEM DOS MATERIAIS}

A usinagem é reconhecidamente o processo de fabricação mais popular do mundo, transformando em cavacos algo em torno de $10 \%$ de toda a produção de metais e empregando dezenas de milhões de pessoas [4].

Como operações de usinagem entendemos aquelas que, ao conferir à peça a forma, ou as dimensões ou o acabamento, ou ainda uma combinação qualquer desses três itens, produzem cavaco. Definimos cavaco, a porção de material da peça retirada pela ferramenta, caracterizando-se por apresentar forma geométrica irregular [5].

\section{III.1 TORNEAMENTO}

Segundo Ferraresi (1977), o torneamento é um processo mecânico de usinagem destinado a obtenção de superfícies de revolução com auxílio de uma ou mais ferramentas. Para tanto, a peça gira em torno do eixo principal de rotação da máquina e a ferramenta se desloca simultaneamente segundo uma trajetória coplanar com o referido eixo [5].

O torneamento utilizado no presente trabalho será o torneamento retilíneo - a ferramenta se deslocando segundo uma trajetória retilínea. Mais especificamente, o torneamento cilíndrico externo, conforme a Figura 01, sendo este um tipo de torneamento retilíneo.

\section{III.2 GRANDEZAS NO PROCESSO DE USINAGEM}

As grandezas envolvidas são padronizadas (ABNT), de modo que os princípios usados nas máquinas e ferramentas permitem obter as superfícies desejadas. A seguir serão apresentadas algumas das grandezas envolvidas no processo de usinagem, de modo a facilitar a compreensão dos conceitos relacionados às diferentes operações de usinagem.

Movimento de corte - ocorre entre a peça e a aresta de corte, e quando ocorre sem o movimento de avanço só retira material da peça em uma única rotação.

Movimento de avanço - ocorre também entre a peça e a aresta de corte, e juntamente com o movimento de corte, possibilita a retirada contínua de material.

Movimento efetivo de corte - é o resultante da composição dos movimentos de corte e de avanço. $v c$ - segundo Diniz et al (2001), é a velocidade tangencial instantânea resultante da rotação da ferramenta em torno da peça, para as operações do tipo torneamento, fresamento ou furação, onde os movimentos de corte e de avanço ocorrem concomitantemente [6].

$$
v c=\pi . d . n 1000[\mathrm{~m} / \mathrm{min}]
$$

Onde:

$\mathrm{d}=$ diâmetro da peça $(\mathrm{mm})$

$\mathrm{n}=$ rotação $(\mathrm{rpm})$

$f=\operatorname{avanço~}(\mathrm{mm})$ $f$ - avanço é o percurso de avanço em cada volta ou em cada curso da ferramenta, [5].

$v f=f . n[\mathrm{~mm} / \mathrm{min}]$

$v f$ - de acordo com [5], a velocidade de avanço é a velocidade instantânea da ferramenta segundo a direção e sentido de avanço.

ap - profundidade de usinagem ou largura de corte [mm] é a profundidade ou largura de penetração da aresta principal de cort, medida numa direção perpendicular ao plano de trabalho, [5].

$b$ - largura de corte define-se como a largura calculada da seção transversal que será retirada, sendo medida na superfície de corte, numa direção normal à direção do corte.

$h$ - espessura de corte, é a espessura calculada da seção transversal de corte a ser retirada e medida, normalmente, à superfície em usinagem principal e segundo a direção perpendicular à direção de corte [7].

$x r$ - ângulo de posição da ferramenta é o ângulo entre o plano de corte da ferramenta e o plano admitido de trabalho, medido sobre o plano de referência da ferramenta. [6]

$\alpha$ - ângulo de folga é o ângulo entre a superfície de folga e o plano de corte da ferramenta [6].

$\gamma$ - ângulo de saída se localiza entre a superfície de saída e o plano de referência da ferramenta [7].

$\beta$ - ângulo de cunha da ferramenta é formado pelas superfícies de saída e de folga [7].

\section{III.3 FURAÇÃO}

A furação, é um processo mecânico de usinagem destinado a obtenção de um furo geralmente cilíndrico numa peça, com auxílio de uma ferramenta multicortante. Para tanto a ferramenta ou a peça se desloca segundo uma trajetória retilínea coincidente ou paralela ao eixo principal da máquina. A furação subdivide-se nas operações:

- Furação em cheio - processo de furação destinado a abertura de um furo cilíndrico numa peça, removendo todo o material compreendido no volume do furo final, na forma de cavaco;

- Furação escalonada - processo de furação destinado à obtenção de um furo com dois ou mais ferramentas especiais;

- Escareamento - processo de furação destinado à abertura de um furo cilíndrico numa peça pré-furada;

- Furação de centros - processo de furação destinado à obtenção de furos de centros, visando uma operação posterior na peça;

- Trepanação - Processo de furação em que apenas uma parte de material compreendido no volume do furo final é reduzida a cavaco, permanecendo o núcleo maciço;

- Alargamento - O alargamento é um processo mecânico destinado ao desbaste ou ao acabamento de furos cilíndricos ou com auxílio de ferramentas multicortantes. Para tanto, a ferramenta ou a peça gira e a ferramenta ou a peça se desloca segundo uma trajetória retilínea, coincidente ou paralela ao eixo de rotação da ferramenta. $\mathrm{O}$ alargador pode ser;

- Alargamento de desbaste - Processo destinado ao desbaste da parede de um furo cilíndrico ou cônico; 
- Alargamento de acabamento - Processo de alargamento destinado ao acabamento da parede de um furo cilíndrico ou cônico;

- Rebaixamento - O rebaixamento é um processo mecânico de usinagem destinado à obtenção de uma forma qualquer na extremidade de um furo, neste processo, geralmente a ferramenta gira e desloca-se simultaneamente segundo uma trajetória retilínea, coincidente com o eixo de rotação da ferramenta;

- Mandrilamento - O mandrilamento é um processo mecânico de usinagem destinado á obtenção de superfícies de revolução com auxílio de uma ou várias ferramentas de barra. Para tanto a ferramenta gira e se desloca segundo uma trajetória determinada;

- Mandrilamento cilíndrico - Processo de mandrilamento no qual a superfície usinada é cônica de revolução, cujo eixo coincide com o eixo em torno do qual a ferramenta gira;

- Mandrilamento cônico - Processo de mandrilamento no qual a superfície usinada é cônica de revolução, cujo eixo coincide com o eixo no qual gira a ferramenta;

- Mandrilamento radial - Processo de mandrilamento no qual a ferramenta é $m$

- Mandrilamento de superfícies especiais - Processo de mandrilamento no qual a superfície usinada é uma superfície de revolução, diferente das anteriores, cujo eixo coincide com eixo em torno do qual gira a ferramenta. Exemplos: mandrilamento esférico e de sangramento;

Quanto à finalidade, as operações de mandrilamento podem ser classificadas ainda em mandrilamento de desbaste e mandrilamento de acabamento.

\section{MISSÃO}

Produção e comercialização de conjuntos de transmissão e outros componentes mecânicos para motocicletas.

\section{IV.1 POLÍTICA DA QUALIDADE}

A empresa metalúrgica do pólo de duas rodas, está comprometida

Atender aos requisitos aplicáveis: clientes, corporativo, normas, legislações, outros requisitos;

Proteger o Meio Ambiente, controlando com responsabilidade as atividades que tem influência, visando a prevenção da poluição; Buscar a melhoria contínua do desempenho do Sistema de Gestão para conquistar a confiança dos clientes, otimizar os processos, otimizar o uso dos recursos naturais, reciclar e reaproveitar os resíduos para evitar impactos ambientais significativos;

Desenvolver seus colaboradores para que todos objetivem uma empresa onde a qualidade esteja no mais alto nível para os seus clientes e tornem-se comprometidos com a proteção ao meio ambiente.

\section{IV.2 FERRAMENTAS}

Para que o Lean Manufacturing consiga atingir os objetivos, é necessário aplicar algumas ferramentas que auxiliarão na obtenção dos resultados. As ferramentas são instrumentos utilizados para implementação de um Sistema de Manufatura Enxuta e aplicação kaizen, que ditam "como" seguir seus princípios. no processo de furo de lubrificação iremos utilizar as ferramentas da qualidade como: Diagrama de causas e efeitos e Gráfico de pareto.

\section{IV.2.1 ANÁLISE DE DADOS}

A linha de usinagem secundária de Eixo transmissão é composta por oito equipamentos, apresentados na Figura 02, sendo: Furo profundo, Torno CNC, Furo de lubrificação e Rebarba , a mesma encontra-se produzindo em dois turnos e gerando vários problemas de qualidade como:

- Furo deslocado

- Quebra de broca

- Retrabalho de peças

- Horas Extras.

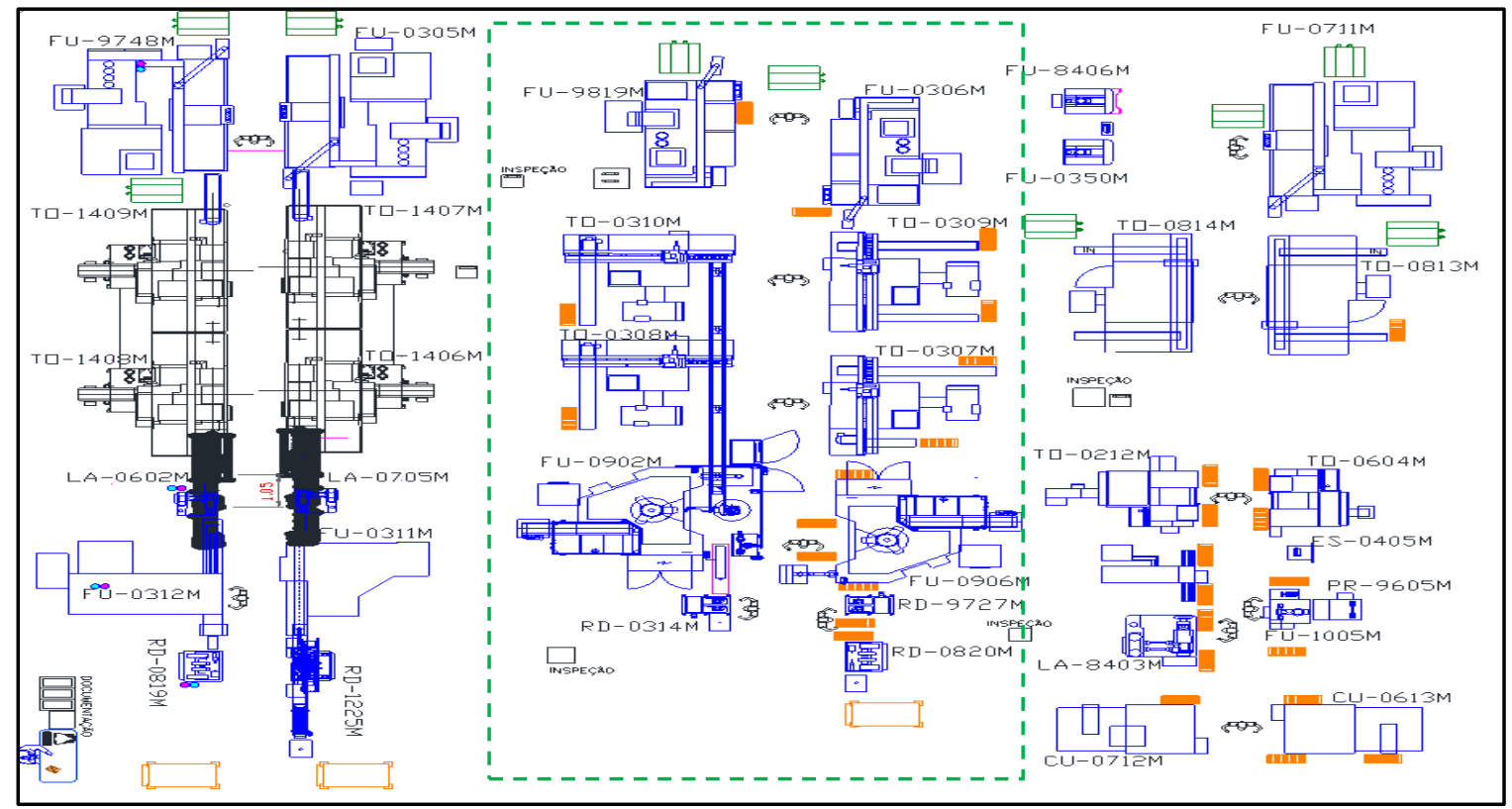

Figura 1 - Layout da linha de Eixo Transmissão.

Fontes: Autores, (2019). 


\section{LINHA SECUNDÁRIA DO EIXO TRANSMISSÃO}

Analisando os dados do setor da linha secundária do eixo transmissão, pode-se observar um alto índice de peças com problemas de qualidade referente ao processo de furo de lubrificação como: furo incompleto, furo deslocado, furo obstruído e peças para serem retrabalhadas conforme segue na Figura 03.

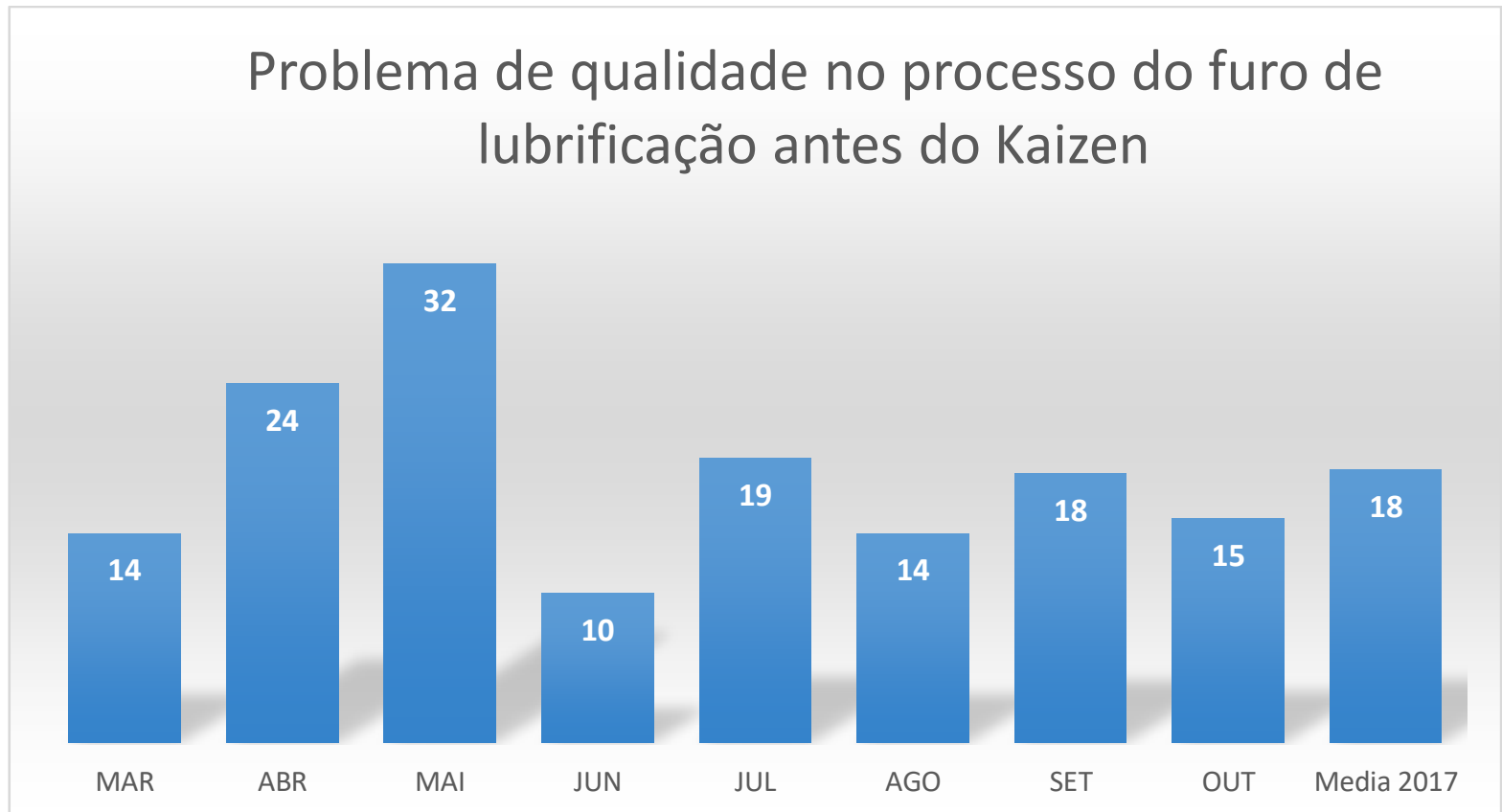

Figura 2 - Problema de qualidade no processo de furo de lubrifição. Fontes: Autores, (2019).

Através da análise feita na linha de usinagem de eixo transmissão, no processo de furo de lubrificação serão utilizadas as ferramentas da qualidade como: Diagrama de causas e efeitos e Gráfico de pareto. De acordo, com o diagrama de Ishikawa podemos observar que temos um problema nas máquinas relacionado as ferramentas utilizadas no processo de furo de lubrificação, como mostra a Figura 04.

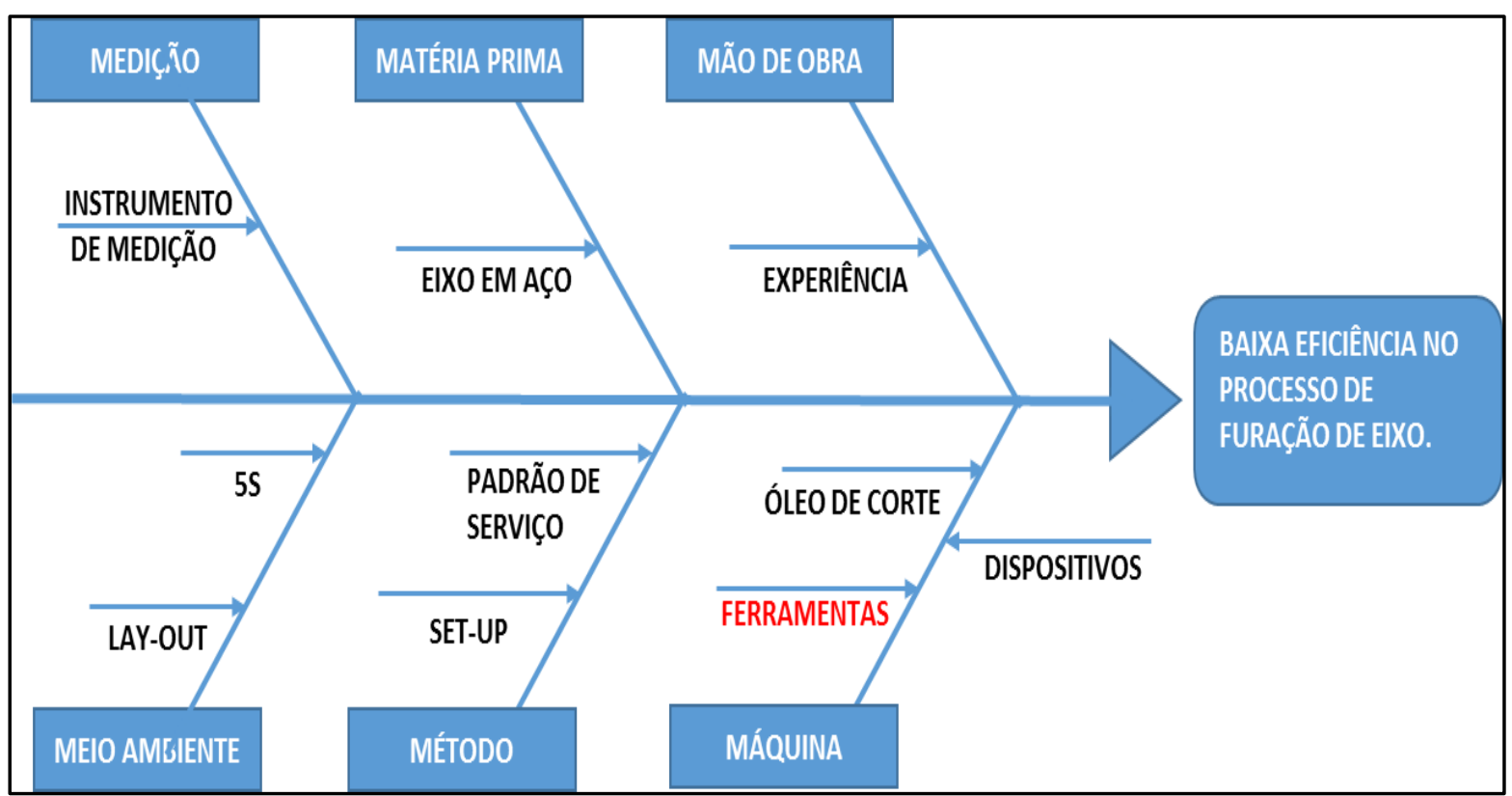

Figura 3 - Diagrama de Ishikawa.

Fontes: Autores, (2019).

Após análise feita na linha de usinagem utilizando a ferramenta da qualidade, Diagrama de causas e efeito (Diagrama de Ishikawa) podemos observar problema referente as ferramentas utilizadas no processo como, desgaste prematuro e quebra das ferramentas referente ao ano de 2017 como mostra a Figura 06. 


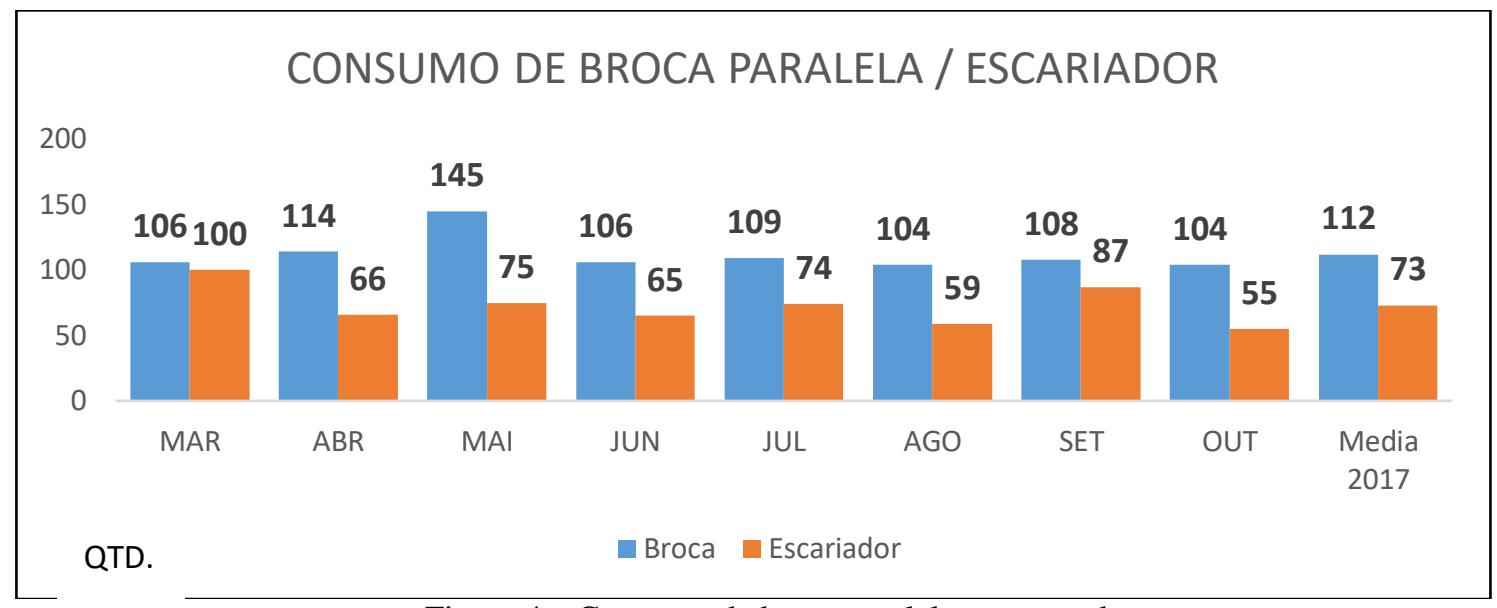

Figura 4 - Consumo de broca paralela e escareador.

Fontes:Autores, (2019).

Os gráficos apontam a capacidade produtiva mensal referente ao pedido do cliente e a capacidade de atendimento da empresa, o que nos possibilita identificar a necessidade de horas extras para atender o pedido do cliente, pois a baixa eficiência da linha requer mais horas diárias de trabalho, conforme segue na Figura 5.

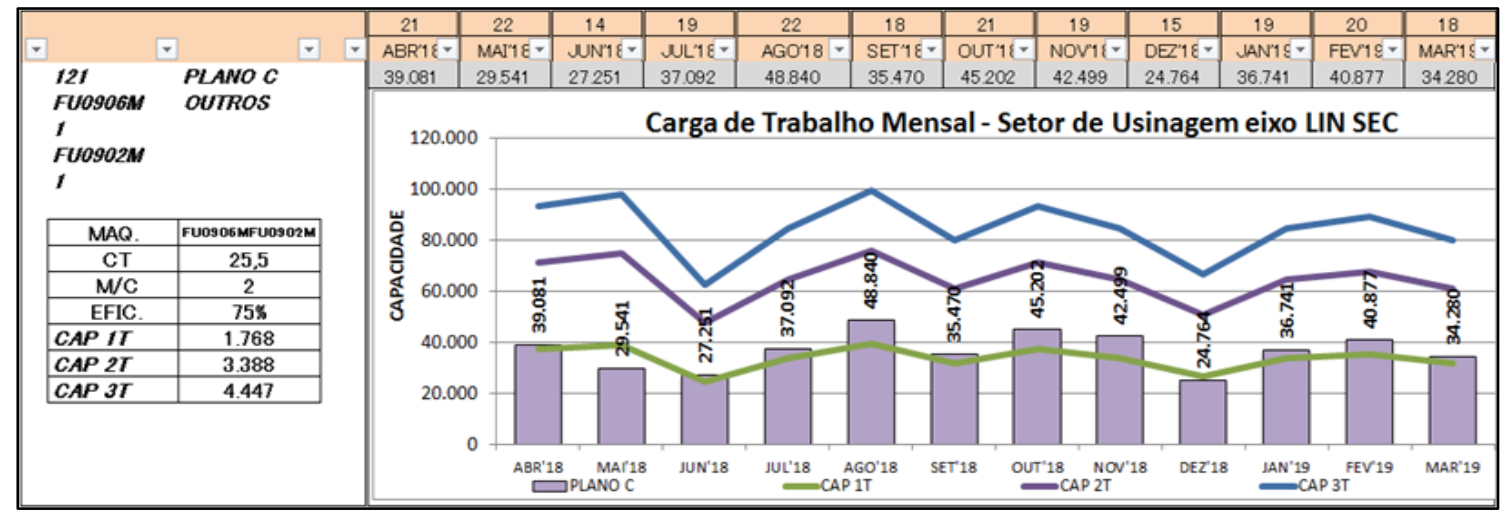

Figura 5 - Gráfico de carga de trabalho mensal da linha.

Fontes: Autores, (2019).

\section{APLICAÇÃO DO KAIZEN}

Após todas as análises realizadas no setor de eixo transmissão, foi realida a troca das ferramentas conforme programado no cronograma. Foi substituída a broca paralela e escareador apresentadas na Figura 6 por uma broca escalonada de acordo com a Figura 7, a broca escalonada realiza o mesmo processo que a paralela e escareador, assim otimizando o processo de furo de lubificação.

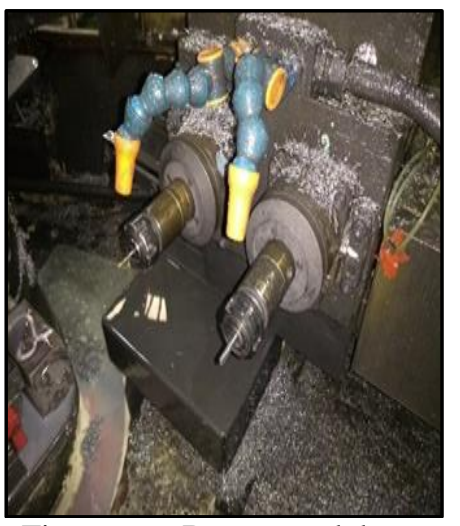

Figura 6 - Broca paralela e escareador.

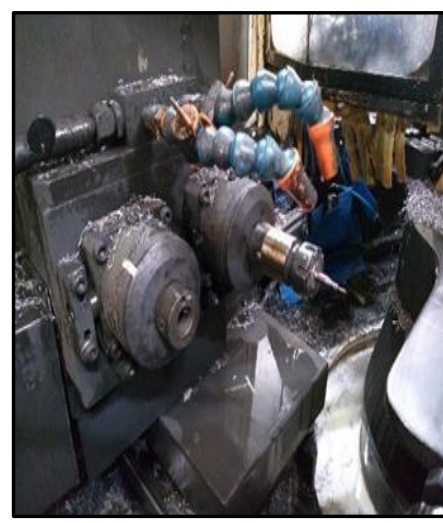

Figura 7 - Broca escalonada. Fontes: Autores, (2019).
Com as mudanças realizadas pelo trabalho (substituição da broca paralela e escareador), pode-se observar que não houve aumento no custo peça/ ferramenta, como indica a Figura 8.

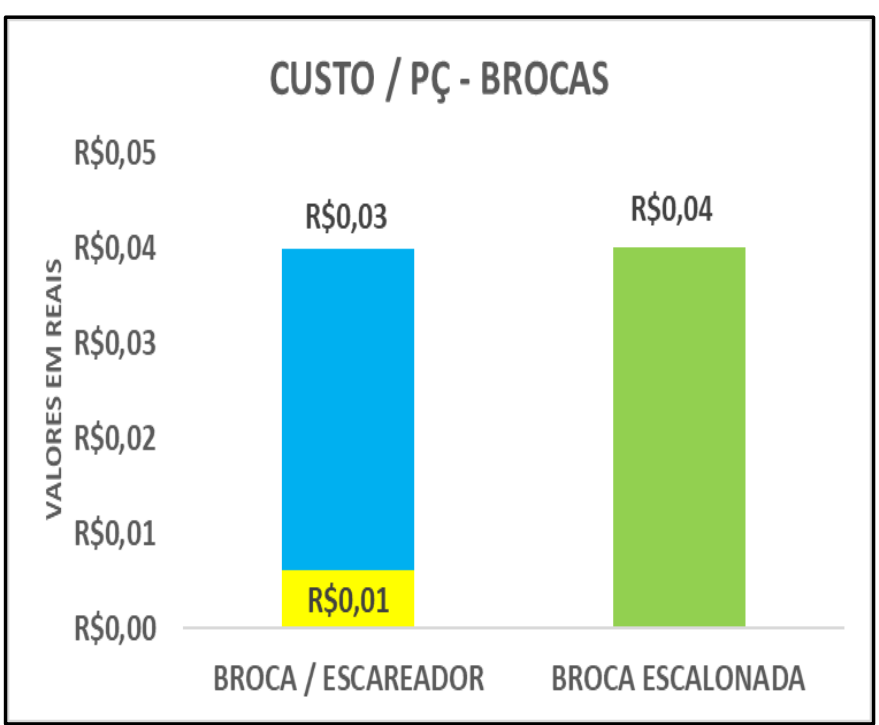

Figura 8 - Gráfico custo peça - brocas. Fontes: Autores, (2019).

Fontes: Autores, (2019). 
Em seguida será mostrado os tempos de processo e balanceamento da linha e como pode-se observar a furadeira FU-0902M encontrase com um tempo elevado conforme a Figura 9.

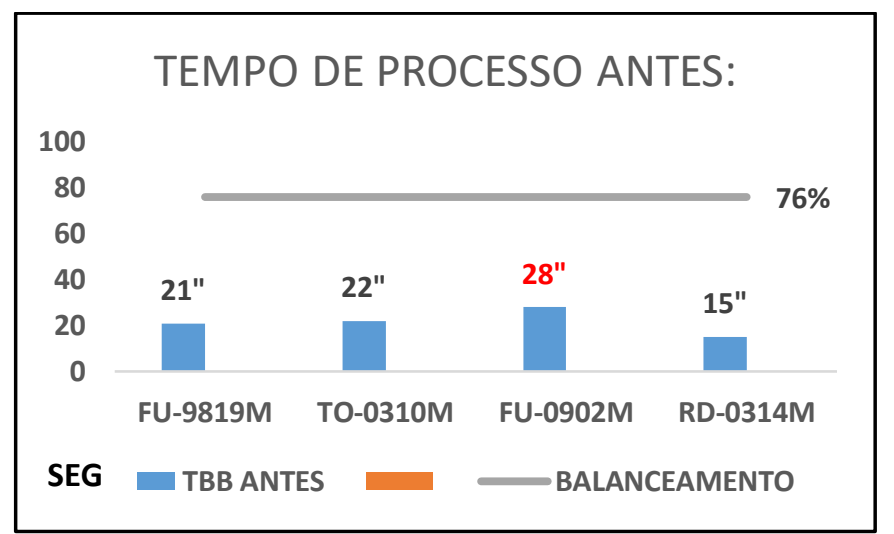

Figura 9 - Tempo de processo de balanceamento da linha. Fontes: Autores, (2019).

Conforme pode-se observar após a troca das ferramentas obteve-se uma redução no tempo na FU-0902, referente ao processo de usinagem de furo de lubrificação como mostra a Figura 10 .

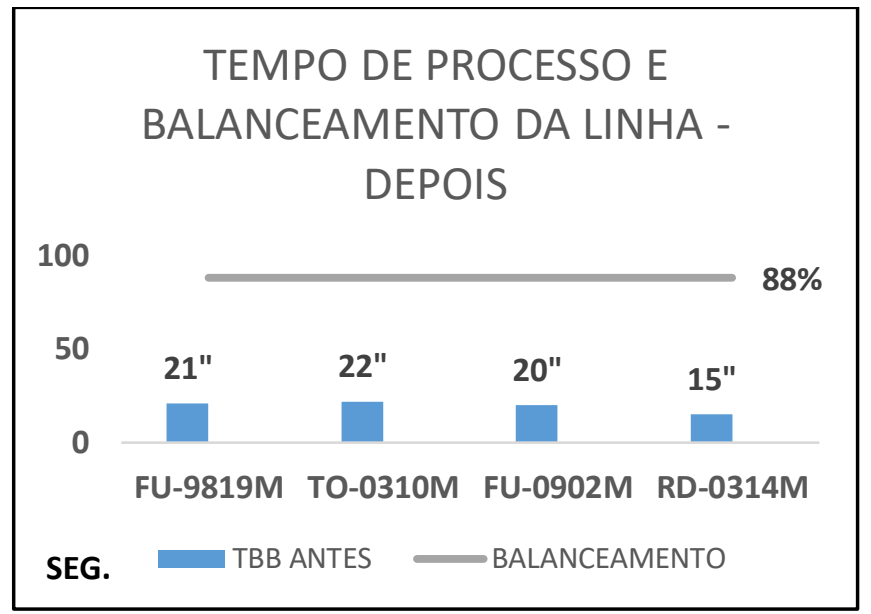

Figura 10 - Tempo de processo de balanceamento da linha após kaizen.

Fontes: Autores, (2019).

Após, Kaizen realizado no processo de furo de lubrificação na linha de eixo transmissão, pode-se observar um ganho considerável na capacidade produtiva e redução de um turno de trabalho, conforme segue na Figura 15.

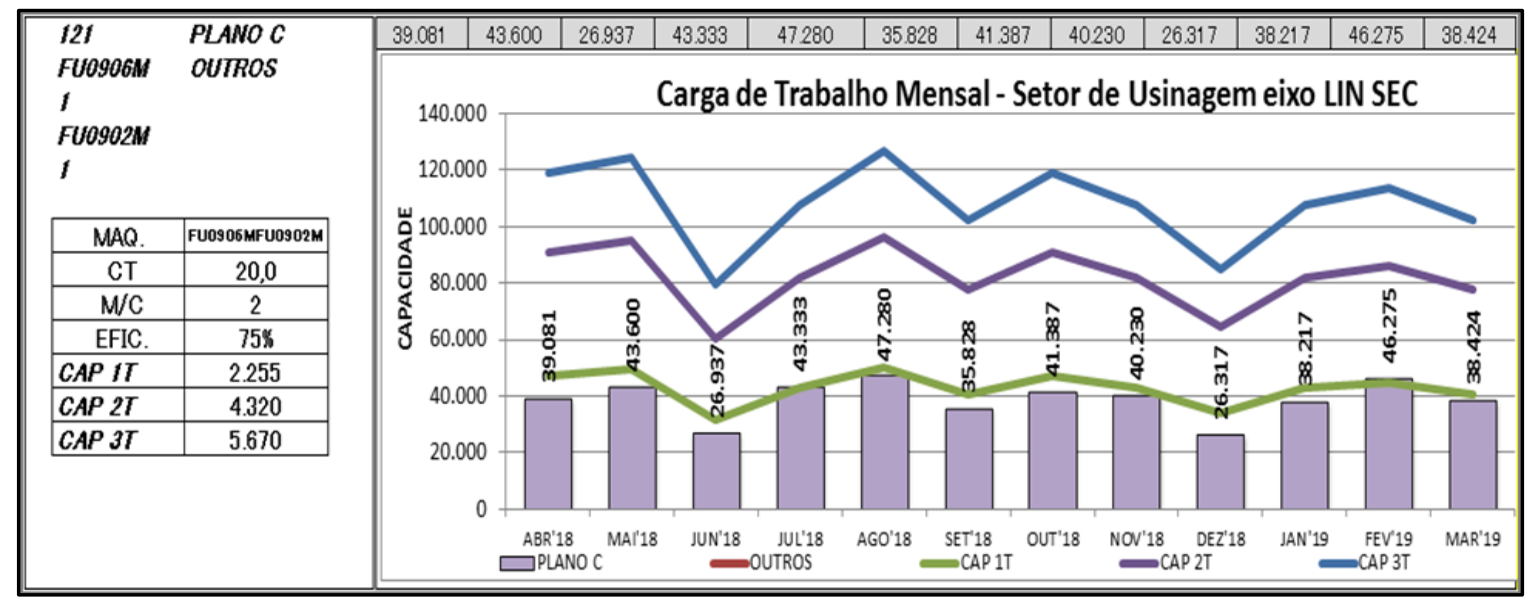

Figura 11 - Gráfico de carga de trabalho mensal da linha.

Fontes: Autores, (2019).

\section{GANHO COM KAIZEN}

Posteriormente, a realização do Kaizen no processo do furo de lubrificação na linha de eixo transmissão, devido a redução do tempo de processo que antes era '25,5" segundos como mostrado na Figura 8 para ' 20 " segundos como apresentado na Figura 10, além disso, pode-se observar uma redução de 7,25\% no custo da peça conforme demostrado na Figura 12.

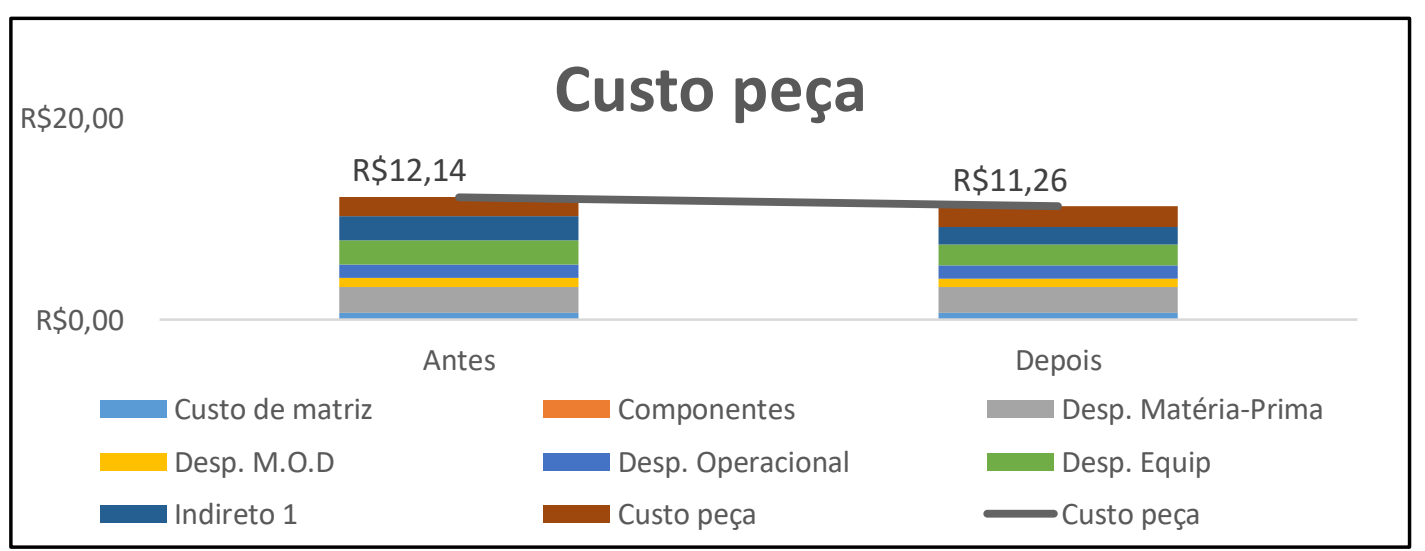

Figura 12 - Gráfico custo peça.

Fontes: Autores, (2019). 


\section{CONCLUSÃO}

Esse trabalho abordou um estudo no processo produtivo na linha de eixo transmissão nas furadeiras CNC de processo de furo de lubrificação, para tal foram aplicados conceitos e ferramentas de análise e solução de problema (Kaizen) realizado na empresa do PIN. Teve como objetivo apresentar melhorias de processo na linha de eixo transmissão nas furadeiras CNC de processo de furo de lubrificação, devido a problemas de qualidade encontrados na linha Secundária de Eixo Transmissão na qual durante a realização das atividades, devido uso da ferramenta inadequada geravam-se muitas perdas e consequentemente a baixa produtividade no processo. Para o levantamento dos dados, foram feitos estudo junto ao processo produtivo, com relação ao índice de perdas e o aumento da eficiência. A finalidade do estudo teve como intuito sanar esses problemas, após uma avaliação feita em loco no chão de fábrica, foi sugerido o teste e troca de novas ferramentas para avaliar o desempenho e o aumento da produtividade da linha a fim de garantir a qualidade do produto e satisfação dos clientes. A proposta foi realizar algumas modificações na linha de produção para avaliar o desempenho, com base nos critérios definidos pela gerência e responsáveis da área, foram estabelecidos as sistemáticas e objetivas para a implementação da melhoria com justificativas de contribuir para a redução das perdas no processo, redução de custos e o aumento da produtividade. Foi sugerido à troca da broca para furadeira e após a implementação da nova sistemática, foi feito um acompanhamento no processo, e como pode ser observado no gráfico (resultados obtidos), foram identificados resultados positivos no aumento da produção e na diminuição das perdas no processo com um ganho $\mathrm{R} \$ 116$ mensais com a troca apenas da ferramenta de uma máquina, já que o equipamento trabalhava em 3 turnos trocando 2 ferramentas/turno. No entanto, as melhorias implementadas no processo produtivo foram eficazes e resultaram em muitos benefícios como redução de custos, redução de mão de obra, ferramenta e consequentemente o aumento do lucro para a empresa. Devido aos ótimos resultados obtidos com a implantação do Kaizen no processo de furo de lubrificação na linha de Eixo Transmissão através do ciclo da qualidade o PDCA, está sendo avaliado as possibilidades de aplicar o kaizen em outras linhas de usinagem referente aos processos de furo de lubrificação como uma revisão lateral.

\section{REFERENCIAS}

[1] Ohno, T. O Sistema Toyota de Produção - além da produção em larga escala. Porto Alegre: Artes Médicas, 1997.

[2] Shinohara, I. New Production System: JIT Crossing Industry Boundaries. Productivity Press, 1988.

[3] Ohno, T. O Sistema Toyota de Produção - além da produção em larga escala. Porto Alegre: Artes Médicas, 1997.

[4] Trent, E. M. Metal cutting. 2 ed. Londres: Butterworths \& Co., 1984.

[5] Ferraresi, D. Fundamentos da usinagem dos metais. São Paulo: Edgard Blücher, 796p, 1977.

[6] Diniz, A. E; Marcondes, F. C; Coppini, N. L. Tecnologia da usinagem dos materiais, $3^{\text {a }}$ Edição - pp. 13 a 74 - Ed. Artliber 2001.

[7] Machado, A. R.; Abrão, A. M.; Coelho, R. T.; Silva.; Bacci, M. Teoria da Usinagem dos Materiais. 2. Ed. São Paulo: Blucher, 2011. 